\title{
O FASCISMO COMO MODELO: INCORPORAÇÃO DA “CARTA DEL LAVORO” NA VIA BRASILEIRA PARA $O$ CORPORATIVISMO AUTORITÁRIO DA DÉCADA DE 1930
}

\author{
Fabio Gentile
}

\begin{abstract}
RESUMO
0 debate sobre a influência do corporativismo fascista na "Era Vargas" polariza-se em torno do confronto entre aqueles que apoiam a tese de que a legislação trabalhista dos anos 1930 seria apenas uma cópia da "Carta del lavoro", e aqueles que querem libertá-la do modelo italiano. Neste trabalho pretendemos seguir um percurso metodológico e conceitual diferente. 0 objetivo é abrir um dialogo entre o debate sobre o fascismo como "fenômeno em andamento" e aquele processo de "circulaçãocompartilhada" de ideias em nível global entre as duas guerras mundiais, de forma a analisar como a "Carta del lavoro" foi recebida e reelaborada na via brasileira para 0 corporativismo autoritário da década de 1930.
\end{abstract}

Palavras-chave: Corporativismo. Fascismo. Autoritarismo. Era vargas. Carta del lavoro.

\footnotetext{
${ }^{1}$ Professor adjunto do departamento de Ciências Sociais da Universidade Federal do Ceará. Brasil. fabio_gentile@ymail.com
} 


\title{
FASCISM AS A MODEL: INCORPORATING THE “CARTA DEL LAVORO" INTO THE BRAZILIAN WAY FOR THE AUTHORITARIAN CORPORATISM OF THE 1930S
}

\begin{abstract}
The debate about the influence of fascist corporatism in the "Vargas Era" is polarized. It features a confrontation between some who support the thesis that the labor legislation of the 1930s was a mere copy of the "Carta del lavoro" and others who want to liberate Brazil's law from the Italian model. In this study, we intend to follow a different methodological and conceptual route. Our objective is to open a dialogue between the debate about fascism as a "phenomenon in progress" and the process of the "shared circulation" of ideas at the global level between the two world wars to analyze how the "Carta del lavoro" was received and redrafted in the Brazilian way for the authoritarian corporatism of the 1930s.
\end{abstract}

Keywords: Corporatism. Fascism. Authoritarianism. Vargas era. Carta del lavoro.

\section{INTRODUÇÃO}

questão da incorporação da "Carta del lavoro" fascista (1927), na legislação $A$ social brasileira das décadas de 1930 e 1940 começa logo após a revolução $\perp$ varguista de 1930 e continua sendo até hoje o centro de uma controvérsia, especialmente no campo jurídico, também em consideração de que o modelo corporativo dos anos 1930 ainda é a espinha dorsal da atual organização sindical brasileira. 0 debate parece polarizar-se em torno do confronto entre aqueles que defendem a tese de que a legislação brasileira é uma "cópia" tout court da "Carta del lavoro" (ROMITA, 2001) e aqueles que tendem a dissociar-se do documento italiano para apoiar a tese da originalidade e novidade das leis varguistas em matéria de proteção do trabalho (BIAVASCHI, 2007). Nem a historiografia mais crítica e documentada sobre 0 assunto parece sair deste impasse, uma vez que reconhece apenas a matriz fascista das leis sociais durante a "Era Vargas" (GOMES, 1988; VIANNA, 1976), sem reconstruir as causas e as trajetórias do complexo processo de assimilação do modelo jurídico arquitetado pelo jurista fascista italiano Alfredo Rocco de forma compatível com um estado que aspirava claramente ao totalitarismo.

Neste trabalho, gostaríamos de abordar a questão da incorporação da "Carta del lavoro" na legislação trabalhista brasileira com um enfoque 
metodológico e analítico mais produtivo para 0 avanço do debate. 0 objetivo é abrir um dialogo entre o debate sobre o fascismo como "fenômeno em andamento" (Paxton, 2005), pensado no "cerne da modernidade do século XX" (Mann, 2004), e aquele processo de "circulação-compartilhada" de ideias em nível global entre as duas guerras mundiais, de forma a analisar como, a partir do modelo italiano, ele foi recebido e reelaborado no nacionalismo autoritário brasileiro entre o final dos anos 1920 e os anos 1930.

0 corporativismo, nas suas várias dimensões (econômica, política, social e jurídica), torna-se então um campo privilegiado de análise para dar uma imagem mais dinâmica do ciclo evolutivo fascista, desde o seu nascimento na Itália durante a Primeira Guerra Mundial até a tragédia da Segunda Guerra Mundial, uma vez que nas intenções de Mussolini e dos seus colaboradores o estado corporativo devia ser a essência do "Estado novo", a ser exibido com orgulho diante todo 0 mundo através da fórmula da "terceira via" fascista, verdadeiramente "revolucionária" entre liberalismo e socialismo. Basta pensar que não só o Portugal de Salazar e a Espanha de Franco, mas também alguns países do Leste Europeu, a Áustria de Dollfuss, a Alemanha nazista por alguns aspectos, e a Argentina peronista apreciaram e utilizaram os princípios da "Carta del lavoro" na construção de seu projeto de governo autoritário e totalitário.

Tendo em conta o estado atual do debate, pretende-se analisar a incorporação da "Carta del lavoro" na construção da via brasileira para 0 corporativismo autoritário, que foi um dos pilares da "Era Vargas" entre a "Revolução de 1930" e a Segunda Guerra Mundial. A escolha desta periodização é necessária, a fim de mostrar que a assimilação do modelo italiano na criação do Estado autoritário e corporativo brasileiro não se limitou apenas à fase ditatorial do "Estado Novo" (1937-1945), mas foi uma operação gradual, cujas raízes teóricas já são detectáveis no debate ideológico e político da Primeira República.

Vamos tratar, portanto, o triunfo do corporativismo durante a era de Getúlio Vargas, tentando responder a algumas das questões que surgiram ao longo da pesquisa.

Como e através de que fontes as ideias corporativas fascistas, tais como "questão social", "nacionalismo social", "Estado nacional do trabalho", "categoria", "contrato coletivo", "Justiça do trabalho", "corporações", "enquadramento sindical", "sindicato único", "produtores da nação", "conselhos técnicos", circularam no Brasil entre os decênios de 1920 e 1930? Como e em que medida os intelectuais e os juristas que auxiliaram Vargas na construção do Estado 
corporativo receberam o modelo de Alfredo Rocco, modificando e adaptando-o de uma forma compatível com a realidade brasileira?

Essas questões são muito complexas, porque colocam dois problemas fundamentais. 0 primeiro problema diz respeito aos diferentes modelos de Estado em que foi colocado o corporativismo. Se no caso do Estado fascista Alfredo Rocco pensou em uma organização corporativa sujeita ao controle rigoroso do partido-estado totalitário, no caso brasileiro, pelo contrário, o corporativismo enquadrou-se em um regime autoritário que não tinha um partido único de massa, mas baseou-se na liderança do presidente.

0 segundo questionamento versa sobre os diferentes níveis econômicos e sociais dos dois Países. Precisamos então entender como foi possível adaptar a um país agroexportador, dependente do mercado internacional, com uma classe operária ainda embrionária, o modelo corporativo italiano, concebido para um país que, desde a segunda metade do século XIX, tinha tomado o caminho da industrialização, incorporando, inclusive, o conflito capital-trabalho típico de uma sociedade industrial avançada.

A nossa hipótese baseia-se na convergência de duas teorias: em primeiro lugar, a análise estruturalista de Juan Linz, que vê o fascismo com um "late comer", um fenômeno ideológico, político e social "retardatário" típico do século $\mathrm{XX}$ - enquanto que as outras ideologias (como o liberalismo e o socialismo) já haviam se manifestado amplamente ao longo do século XIX - que se expande rapidamente e simultaneamente numa época tanto de crise das instituições liberais e de afirmação do socialismo (dos quais o fascismo quer subtrair "espaço político"), quanto de expansão do autoritarismo, tendencialmente de direita (LINZ, 1976). Em segundo lugar, a teoria do "desenvolvimento tardio", em sua variante nacionalista, segundo a qual alguns países da "periferia" do capitalismo privilegiaram o Estado autoritário como centro organizador da nação em todos os seus aspectos, tendo em vista superar o atraso e quebrar a dependência que tinham dos países mais desenvolvidos (CARDOSO; FALETTO, 1970).

Nesta perspectiva, o corporativismo fascista apareceu e foi percebido pelos teóricos do autoritarismo brasileiro como o modelo mais moderno, para a época, de reorganização das relações entre Estado, indivíduo e mercado. Perante a decadência do "artificialismo" da Velha República liberal, a via brasileira para 0 corporativismo autoritário tomou a forma de uma apropriação criativa do repertório (bem como da linguagem) fascista, em um contexto histórico diferente daquele italiano da década de 1930. No caminho traçado pela revolução de 1930 em território brasileiro, Getúlio Vargas e os arquitetos do Estado Novo 
apresentaram a industrialização como a via para reconstruir a economia nacional, após a crise de 1929 - que havia mostrado a dependência do café, o principal produto da economia agroexportadora brasileira, expondo a fragilidade da economia nacional frente ao mercado global. E o Estado corporativo autoritário se tornou 0 principal instrumento para governar a transição para a civilização industrial.

Um dos principais fundamentos teóricos dessa visão foi o conceito de corporativismo "integral" e "puro" do economista e político romeno Mihail Manoilescu (1938) ${ }^{2}$, elaborado de acordo com os diferentes níveis econômicos e políticos de cada país para resolver tanto a crise econômica das áreas avançadas, quanto para coadjuvar o take off industrial da "periferia" do capitalismo. Com base na ideia de que as nações periféricas do capitalismo poderiam romper 0 vínculo de dependência semicolonial que tinham em relação aos países mais desenvolvidos, Mihail Manoilescu previa a implantação de um Estado forte, capaz de organizar integralmente todos os recursos nacionais para projetar a transformação necessária e irreversível da sociedade agrária para a sociedade industrial. Embora as massas trabalhadoras da "periferia" do capitalismo ainda não tivessem chegado num nível de organização e consciência de classe comparável aos dos países mais industrializados, também nessa área a transição pela era industrial, dominada pela organização e pela técnica, devia ser coadjuvada por uma política preventiva, orgânica à centralização capitalista, de incorporação da classe operária, ainda em embrião, no Estado, para evitar a reprodução do conflito de classes da sociedade europeia durante a Primeira Guerra Mundial.

Nesta perspectiva, o corporativismo fascista - em suas múltiplas dimensões de catalogação jurídica do social, dirigismo econômico, organização da nação e harmonização do conflito capital-trabalho - encaixou-se perfeitamente no projeto nacional desenvolvimentista, autoritário e estadocêntrico de Getúlio Vargas de modernização corporativa da sociedade brasileira entre as duas guerras mundiais.

\footnotetext{
${ }^{2}$ Seguidor do fascismo italiano, Manoilescu foi um dos autores mais populares do debate brasileiro dos anos 1930. Sua obra mais famosa - O século do corporativismo (1934) - foi traduzida do francês para o português por Azevedo Amaral, um dos principais ideólogos do Estado Novo, em 1938. Por "integral" entende-se um modelo de corporativismo não limitado apenas ao dirigismo econômico, mas que engloba todas as forças sociais e culturais da nação. Por "puro" refere-se à centralidade das corporações como fontes de poder do Estado.
} 


\section{O CORPORATIVISMO ITALIANO: DO SINDICALISMO NACIONAL À “CARTA DEL LAVORO”}

Para os fins de nossa análise teórica sobre a incorporação da "Carta del lavoro" na legislação trabalhista, precisamos relembrar as etapas essenciais que constituíram o modelo italiano. Na origem do corporativismo fascista há a doutrina fundamental do sindicalismo nacional, que se afirma na Europa em princípio do século XX (principalmente na França, na Itália, na Inglaterra, na Alemanha, na Suíça e na Polônia) e se fundamenta na socialização da economia entregue às categorias do trabalho e da produção em todas as suas manifestações, que não deviam mais ser enquadradas no esquema marxista capitalismoproletariado, mas tinham que ser repensadas à luz das novas transformações aportadas pela técnica, pela administração e pela organização empresarial.

0 seu programa teórico-político embasa-se na aversão pelo regime liberalrepresentativo, no desenlace do sindicado e do trabalho dos dogmas do marxismo e na centralidade do trabalho nos processos de transformação política, economia e social do Estado como fundação da nação (o "Estado nacional do trabalho"). Neste modelo, só os "produtores", identificados pelo sua condição profissional, gozam plenamente do status de cidadãos da nação. Porém, deve-se ao jurista Alfredo Rocco (Nápoles 1875 - Roma 1935) a transformação do sindicalismo nacional em "sindicalismo jurídico", pressuposto para a construção do Estado corporativo, após o fascismo ter chegado no poder em 1922.

0 modelo de Rocco é o ápice de uma trajetória ideológica e política coerente desde a adesão ao movimento nacionalista. Vale a pena examiná-la rapidamente. No nacionalismo conservador do jurista italiano, o ponto de partida é a crítica ao liberalismo, formulada através de alguns elementos fundamentais que se entrelaçam entre si: o problema da relação autoridade-liberdade e 0 problema das massas amorfas produzidas pela modernização.

0 horizonte teórico de referência para Rocco é a escola jurídica alemã do positivismo legal. Pensamos em Georg Jellinek, o qual, em Sistema dos direitos públicos subjetivos (1892), teoriza o conceito de "auto-obrigação do Estado" como fundamento dos direitos individuais. Em síntese, é o Estado - e não o indivíduo - o sujeito originário e representante do interesse geral e da soberania. Os direitos individuais têm sua origem na vontade do Estado de ser vinculado não por outras normas, mas pela autolegislação da razão que deve ser vista como uma auto-obrigação do Estado às próprias leis. Segue então que a liberdade individual está na autolimitação do Estado em relação ao direito que ele mesmo criou. 
Mas como é reelaborado no pensamento nacionalista e depois naquele fascista 0 conceito da auto-obrigação do Estado em relação às próprias leis? Enquanto na tradição jurídica liberal a ideia de autolimitação do Estado é a base legal sobre a qual fundamenta-se a liberdade do cidadão no Estado de Direito, Rocco opera uma verdadeira torção do positivismo jurídico, sendo que a autolimitação do Estado, codificada pela escola organicista alemã e pela tradição italiana, assume a forma de um Estado nacional que transcende a vida de cada individuo e de sua liberdade. 0 conceito de nação, associado a uma ideia de Estado autoritário, dotado de um poder executivo depositário e órgão de todas as funções do Estado genericamente consideradas, termina por negar tanto a tradição liberal democrática quanto o socialismo.

Em um dos textos básicos sobre o nacionalismo italiano (ROCCO, 1914), Rocco expõe os princípios da doutrina nacionalista italiana. 0 limite fundamental do liberalismo - assim como do socialismo, que a seu ver, possui a mesma raiz individualista - está na garantia dos direitos individuais, enquanto que para 0 nacionalismo o princípio fundamental reside na ideia que 0 individuo vive e se realiza em sua nação, entendida como uma sociedade dotada de existência transcendente.

Nesta visão, conciliam-se idealismo e positivismo. São ideias que expõem claramente as bases da ideologia nacionalista, que tende ao fascismo totalitário: a organização das massas no Estado-nação. As massas emersas na história são amorfas. Devem ser enquadradas dentro de organismos com fins superiores aos dos singulares componentes e isto pode ser obtido, somente, através de uma atividade de paciente organização (nação, sociedade, Estado), onde há uma fusão total entre a nação e o Estado. Esta é a moldura filosófico-jurídica sobre a qual se fundamenta o modelo italiano consagrado pela lei de 3 de abril de 1926 "Sobre a disciplina jurídica das relações coletivas do trabalho", pela criação do ministério das Corporações, e pela "Carta del lavoro", o manifesto programático do projeto corporativo fascista.

0 próprio Rocco ilustrava a arquitetura jurídica das novas relações entre capital e trabalho: reconhecimento jurídico dos sindicatos, concentração da representação das categorias num só sindicato, disciplina dos contratos coletivos estipulados por este sindicato com defesa erga omnes, instituição da magistratura do trabalho e, finalmente, proibição de greve e bloqueios, punidos como crime (ROCCO, 2005, p. 311).

De acordo com um trabalho recente (GAGLIARDI, 2010, p. 38), a grande novidade (e ao mesmo tempo o sentido mais profundo) da lei Rocco foi a 
construção de um corporativismo autoritário moderno. Não foi uma simples negação dos elementos constitutivos da sociedade industrial, mas a absorção em sua própria esfera. A parcialidade dos interesses sindicais na totalidade do Estado. Esvaziou-se a sua capacidade de representação antagônica de sujeitos fora do Estado, para incorporá-los e legitimá-los como órgãos públicos, em busca do papel original do Estado como organizador da sociedade. 0 Estado torna-se a nova fonte de legitimidade dos sindicatos: não mais os trabalhadores.

Sobre os quatro pilares fundamentais da lei de 1926 construiu-se a "Carta del lavoro", a qual representou, por sua vez, o compromisso entre as diversas concepções corporativas dentro do fascismo. Em continuidade com a lei de 1926, a "Carta del lavoro" terminava por ser a única reafirmação dos princípios corporativos, sinteticamente exposta em breve documento, composto por trinta enunciações agrupadas em quatro blocos sobre a natureza do Estado corporativo e a sua organização, o contrato coletivo de trabalho e as garantias do salário, os guichês de emprego e enfim previdência, assistência, educação e instrução.

A "Carta del lavoro" teve uma grande ressonância internacional. Ela foi estudada, comentada e utilizada em países que se inspiravam claramente na doutrina corporativa do fascismo para a elaboração de suas políticas sociais e econômicas.

\section{CIRCULAÇÃO DAS IDEIAS FASCISTAS E CORPORATIVISTAS APÓS A “REVOLUÇÃO” DE 1930}

Entre a segunda metade dos anos 1920 e os primeiros anos da década de 1930, o fascismo penetrou no Brasil através de organizações políticas, revistas, jornais e livros, sobretudo de natureza jurídica (VIANNA, 1943, p. 27). Do ponto de vista ideológico, chegou a ganhar mais força depois da revolução de 1930, quando a nova elite governante, liderada por Getúlio Vargas, pretendeu enfrentar a crise do liberalismo da Velha República com um projeto de Estado autoritário, embora a Constituição de 1934 seja ainda um compromisso entre 0 liberalismo e 0 autoritarismo. Na verdade, o próprio Getúlio Vargas, na véspera da revolução, não fez segredo de sua admiração pelo fascismo. Em um discurso de 1929, ele chegou a dizer: "A minha diretriz no governo do Rio Grande [...] se assemelha ao direito corporativo ou organização das classes promovida pelo fascismo, no período da renovação criadora que a Itália atravessa." (VARGAS, 1938, p. 150). 
Neste sentido, Vargas tentava uma conciliação entre a sua visão positivista e castilhista do indivíduo totalmente absorvido no coletivo e o primeiro modelo de Estado Nacional que enfrentava a questão social de forma autoritária. Acima de tudo estava a ideia do superior interesse do Estado (Artigo I da "Carta del lavoro"). Cabe ressaltar que, nesta organização totalitária do Estado-nação, os sindicatos não são livres, mas apenas ferramentas criadas para organizar o trabalho em todas as suas manifestações.

No plano teórico encontramos esse princípio do sindicalismo nacional bem desenvolvido em Problemas de Política Objetiva (1930) de Vianna, um dos maiores pensadores do autoritarismo brasileiro. Neste trabalho, um verdadeiro divisor de águas entre a sua produção dos anos vinte e aquela dos anos trinta, Vianna, talvez o principal teórico da via brasileira para o Estado corporativo, encontra inspiração no filósofo do direito italiano Sergio Panunzio ( $O$ sentimento do Estado, 1929). o conceito-chave do livro de Panunzio é o "sindicalismo nacional", nascido do encontro entre a teoria orgânica da sociedade de Durkheim (a divisão do trabalho social), o sindicalismo integral de Georges Sorel e a valorização do conceito de trabalho em todas as suas articulações no Estado nacional.

A originalidade política e social do fascismo residia, portanto, na fusão do sindicalismo e do nacionalismo. E Vianna, ciente de que as formas típicas de estruturação da sociedade brasileira estavam mudando sob o impulso da modernização dos anos 1920, assimila pela leitura de Panunzio o conceito de organização nacional, que será um dos pilares durante o período em que presta consultoria para o Ministério do Trabalho.

Do encontro com o fascismo, estudado por meio do estado sindical corporativo de Panunzio, o autoritarismo de Vianna recebe uma nova base teórica para resolver a crise do Estado liberal, reduzido a um centro de relações políticas vazias, longe das forças sociais, simples garantia da coexistência interindividual, sem meios para enfrentar o problema do governo da sociedade de massa. Também sob o aspecto mais prático, os conceitos de "superior interesse da nação", "sindicalismo nacional" e "colaboração entre as classes" exerceram profunda influência após a Revolução de 1930. No discurso do Rotary Club (ocorrido em dezembro de 1930), o Ministro do Trabalho, Lindolfo Collor, argumentava que:

A regularização jurídica das relações entre 0 capital e 0 trabalho obedecerá, pois, entre nós, ao conceito fundamental de colaboração 
das classes. Não há nenhuma classe, seja proletária, seja capitalista, que possa pretender que os seus interesses valham mais do que os interesses da comunhão social. 0 Brasil primeiro, depois os interesses de classes (COLLOR, 1990, p. 187).

0 principio do enquadramento jurídico do sindicato é o fundamento da lei sindical $n^{0}$. 19.970, de 1931, que regula a sindicalização das classes patronais, operárias e dá outras providências. Também o próprio Vargas se manifestou sobre a importância desta lei no discurso pronunciado em maio de 1931, salientando a importância da colaboração de classe das organizações sindicais no mecanismo dirigente do Estado (VARGAS, 1943, p. 209).

Sabe-se que a necessidade de atentar para a ordem econômica e social conforme os princípios da justiça e de homogeneizar a vida nacional foi a maior tarefa do governo provisório liderado por Getúlio Vargas. Entre a Revolução de 1930 e a Constituição de 1934, passando pelo processo constitucional, o Estado sindical corporativo, afastado do projeto de simbiose totalitária entre partido fascista, Estado-nação e sindicato, apresenta-se como um caminho privilegiado para colmar o defeito de conteúdo social do Estado moderno. Este eleva, então, a vida social ao plano da vida política com a condição de integrar a sociedade, em suas múltiplas articulações e subdivisões, em um projeto de "Estado Novo" comprometido (sob o efeito da crise da ordem liberal) a repensar sua soberania entendida como reapropriação total do espaço público por um processo de integração dos poderes e das forças sociais baseados no direito, e com o auxílio do sindicato, instrumento privilegiado de transformação corporativa do Estado.

0 modelo corporativo do fascismo influenciou o cenário de profunda transformação econômica, política e social após a Revolução de 1930. Enquanto os técnicos do governo Vargas estavam reformulando os pilares da "Carta del lavoro" numa nova veste jurídico-política, o próprio Vargas expôs as diretrizes do "trabalhismo", cerne da sua política social (GOMES, 1988). Inspirado pelo conceito de trabalho como um dever social do indivíduo enquadrado no Estado nacional, tal como previsto no segundo princípio da "Carta del lavoro", em discurso de 1933, o então presidente convidava a Assembleia Constituinte a reajustar a vida nacional considerando a centralidade do trabalho como fundamento da vida nacional do país e do status de cidadão brasileiro, a cooperação entre empregados e empregadores, a sindicalização das classes e a justiça do trabalho (artigos I-XII da "Carta del lavoro"), levando o problema para 0 âmbito do novo Direito corporativo, que se afirmou em consequência da 
imprescindível necessidade de enquadrar no Brasil o fenômeno da organização coletiva dos interesses e do conflito capital/trabalho, assim como estava acontecendo no plano internacional.

Ficava claro, portanto, que os problemas jurídicos tornaram-se problemas de "categoria". Após a crise do liberalismo, o Estado contemporâneo estava retomando todas as suas prerrogativas - governo, poder e corporativismo - para organizar o fenômeno moderno das "pluralidades coligadas" em uma catalogação total do "social" baseada nas "categorias", dando continuidade à tradição do ius positum e ultrapassando o férreo modelo totalitário italiano.

Por fim, não nos parece muito produtivo retomar as trinta declarações da "Carta del lavoro", comparando-as com os artigos nº 136-140 da Constituição do Estado Novo (de 1937), ou com o decreto lei $n^{\circ} 1237$ (de 1939, que organiza a justiça do trabalho) ou ainda com o decreto $n^{\circ} 1402$ (também de 1939, que institui o sindicato único) para comprovar a tese da cópia, porque o próprio fascismo italiano se apropriou de forma original do debate francês e alemão sobre o Estado social, a questão da "democracia social" e a teoria jurídica do contrato coletivo de trabalho.

0 que nos interessa é entender como e em que medida as ideias de fascismo e corporativismo foram incorporadas aos processos de ruptura da ordem liberal da Primeira República e contribuíram para a formação do Estado brasileiro contemporâneo durante a "Era Vargas".

\section{A “REVISTA DO TRABALHO": UM LABORATÓRIO DE IDEIAS PARA A VIA BRASILEIRA DO ESTADO CORPORATIVO}

$\mathrm{Na}$ perspectiva de ver o modelo corporativo fascista em termos de circulação das ideias, pretendemos analisar a "Revista do trabalho", pois ela foi um dos principais laboratórios intelectuais sobre a chamada "questão social", bem como sobre a modernização do país durante o governo varguista.

Embora a revista tivesse mantido uma continuidade na postura a respeito da "questão social" durante toda a sua existência, o nosso recorte cronológico divide-a em dois períodos, o primeiro de 1933 a 1935 e o segundo de 1937 a 1944. 0 primeiro momento (1933-1935) é o de construção da legislação socialtrabalhista junto com o estudo da questão social brasileira, confrontando-a com os principais países do mundo ocidental desenvolvido; o segundo momento, do Estado Novo, é a fase da consolidação de um direito trabalhista brasileiro. 
Fica claro que nos interessa ver a apropriação do direito corporativo fascista dentro da legislação trabalhista brasileira de 1930. Em aberta polêmica com 0 liberalismo da Velha República, representada como incapaz de lidar com a questão social reduzida a simples "caso de polícia", Vargas e os outros líderes da Revolução de 1930 receberam o corporativismo italiano como o modelo mais moderno, em função da época de inclusão social através do sindicato, bem como de implantação da "democracia social", da harmonia e da paz social em lugar do conflito de classes.

A "Revista do trabalho" nasce em outubro de 1933 na fase de consolidação da Revolução de 1930. Desde o começo se afirma como uma das referências no campo da jurisprudência trabalhista, bem como um órgão técnico a serviço do governo provisório, tendo como objetivo principal o estudo e o debate do problema da regulamentação do trabalho no Brasil, em confronto com as principais legislações dos países que já estavam a caminho da incorporação da questão social no Estado. A investigação científica e 0 estudo positivo dos fatos sociais são, porém, os fundamentos da revista.

Criada por Gilberto Flores, seu diretor responsável de 1933 a 1949, 0 mensário de legislação social teve como diretor técnico, desde o número 13 de janeiro de 1935, Helvécio Xavier Lopes, procurador de trabalho. A revista deixou de ser publicada em 1965.

A maioria dos artigos é ligada ao projeto político de fundo da revista: destacar a poderosa e inovadora obra de implantação de uma legislação social pelo governo provisório a partir da Revolução de 1930, um verdadeiro "marco zero" da política social brasileira nos domínios do Direito do trabalho.

A revista incluía um editorial de abertura não assinado, uma seção doutrinária onde se destacam artigos dos principais juristas da época — Vianna, Evaristo de Moraes Filho, Joaquim Pimenta, Hisose Pimpão, Cavalcanti de Carvalho, Dorval Lacerda, Oscar Saraiva, Epaminonda de Carvalho, Arnaldo Sussekind, J. de Segadas Vianna - , do pessoal técnico do Ministério do Trabalho, e também traduções de artigos de intelectuais estrangeiros da área jurídica trabalhista. Havia ainda uma seção de informações sobre as principais legislações trabalhistas do mundo que lançava o olhar sobre os outros movimentos sindicais e uma seção mais técnica incluindo a legislação com comentários e pareceres.

0 recorte 1933-1935 se caracteriza por dois temas dominantes: a intervenção do Estado para enfrentar o conflito de classes nos países avançados ou em via de desenvolvimento (através da criação de uma legislação trabalhista, da incorporação do sindicato e da regulamentação jurídica do dissídio coletivo) e 0 
Estado corporativo como modelo estatal, visto como uma possibilidade de impor ordem à crise do capitalismo e à crise do Estado liberal, sem necessariamente cair no totalitarismo fascista.

Ao lado da "questão social", que constitui o leitmotiv da revista ao longo da sua existência, o tema central enfocado para o recorte 1937-1944 é o problema da introdução do princípio fascista do poder normativo da magistratura do trabalho. Essa foi a principal acusação do jurista Waldemar Ferreira à Oliveira Vianna. Sobre 0 assunto, a revista toma uma posição bem firme em defesa da justiça do trabalho como corolário da grande obra social da revolução de 1930. 0 outro grande tema é 0 decreto-lei $\mathrm{n}^{\circ} .1 .402$ que institui 0 sindicato único. Aqui os artigos da revista defendem a originalidade do modelo sindical brasileiro, mistura harmoniosa dos Direitos privado e público.

Precisamos então ver como estes juristas, durante os anos 1930, adaptam 0 modelo corporativo fascista, criado por A. Rocco, à realidade brasileira. A maioria dos textos utiliza o léxico e as argumentações reelaboradas pela principal literatura jurídica fascista da época. Desde os primeiros artigos, o tom da autodefesa frente à acusação de ter copiado o fascismo é presente. Nele percebe-se uma hábil e fina tentativa de desenganchar o corporativismo e 0 sindicato do férreo modelo do Partido-Estado totalitário fascista (PIMENTA, 1934, p. 15-17), levando o discurso no âmbito da relação entre a tradição jurídica e o novo Direito corporativo, que se afirmou em consequência da imprescindivel necessidade de colher o fenômeno da organização coletiva dos interesses e do conflito capital-trabalho a nível internacional e, portanto, não limitado ao caso do fascismo italiano (VIANNA, 1933, p. 13).

Com base nas melhores contribuições da ciência jurídica italiana (CARNELUTTI, 1927; RANELLETTI, 1937), este pessoal mostra como o modelo corporativo quer resolver, no mesmo jeito do modelo liberal no século XIX, o problema da ordem social no século XX, indo além das fronteiras da tradicional lógica dicotômica: ou privado ou público, ou lei ou contrato.

Se a Primeira guerra mundial havia declarado o fim da velha ordem do século XIX, o novus ordo do século XX, caracterizado pela ampliação das forças sociais e dos grupos de interesse, necessitava de uma reconsideração completa das modalidades da relação entre indivíduo, sociedade e Estado. Mas se o modelo de corporativismo teorizado na "Revista do trabalho" recalca em boa medida 0 modelo corporativo da "lei Rocco" e da "Carta del lavoro", como os juristas colaboradores da legislação social varguista podem sair do impasse de "imitar" uma organização corporativa estatal, que nas intenções explícitas de seu criador A. 
Rocco tinha que ser a essência do totalitarismo fascista? Como eles podem justificar normas fascistas como o poder normativo da magistratura do trabalho, 0 contrato coletivo, o sindicato único e a proibição de greve no Direito do trabalho brasileiro?

Mais uma vez a "Revista do trabalho" desengancha a sua visão de corporativismo autoritário do totalitarismo fascista referindo-se principalmente à literatura jurídica italiana da época. Trata-se de recuperar uma explicação "redutiva" da novidade introduzida por Rocco no Direito corporativo italiano, que tende a evidenciar os elementos de continuidade entre a construção do jurista napolitano e a tradição jurídica.

Prevalece uma tendência técnico-jurídica e, portanto, "neutra", para dissociar a norma do contexto político, tirando assim aquela sua real incidência na transformação da sociedade. De qualquer forma, os juristas da "Revista do trabalho" tendem a colocar a novidade da lei corporativa italiana no quadro do ius positum. A lei italiana de 1926 é ao mesmo tempo interpretada como uma restauração da tradicional soberania estatal (que havia se perdido na crise do liberalismo), o início de uma nova fase (caracterizada pela organização corporativa das ligações entre indivíduo, sociedade e Estado, indo além do fascismo para alcançar outras metas, como a "democracia social-corporativa") e um Estado sindical-corporativo (capaz de enfrentar a questão social, enquadrado na lógica panunziana da ditadura autoritária como característica permanente do poder político).

Vamos agora a focar o nosso interesse sobre um dos temas dominantes da revista durante o Estado Novo: a acusação, feita por Waldemar Ferreira à Oliveira Vianna de ter introduzido o princípio fascista do poder normativo da magistratura do trabalho nas publicações do periódico (FERREIRA, 1937; VIANNA, 1938). A defesa de Oliveira Vianna é articulada em volta da "temática redutiva" do projeto de Alfredo Rocco, analisando dois dos maiores juristas italianos, o processualista Francesco Carnelutti e Oreste Ranelletti, grande experto de direito público (VIANNA, 1938, p. 78).

Colocando-se na linha de Carnelutti, Vianna vê na lei Rocco a defesa da vocação ordinária do Direito, a ser configurado como composição de um conflito intersubjetivo. A lei de 1926 harmonizou a nova dimensão do coletivo, emersa pela industrialização e ao mesmo tempo projetou o Estado no "social", já que é a mesma vocação social do homem procurando 0 instrumento para regular a pacífica convivência entre os sujeitos que compõem a sociedade. É uma leitura que tende a ver na lei de 1926 o movimento do debate para o regulamento do 
conflito individual do trabalho no plano do conflito coletivo, entendido como aglomeração de uma série homogênea de conflitos individuais (CARNELUTTI, 1927, p. 43; VIANNA, 1938, p. 150). A ideia baseia-se no princípio de interesse de categoria. Para Carnelutti, o interesse coletivo não se distingue pelo interesse dos trabalhadores. Logo, a grandeza da lei de 1926 está no fato de ter harmonizado pacificamente a sociedade. Esse é seu juízo:

0 mecanismo do contrato e do processo coletivo, idêntico àquele do contrato e do processo individual consiste exatamente naquilo que 0 interesse público encontra a sua tutela em virtude do contraste entre duas ações determinadas por dois interesses privados (CARNELUTTI, 1927, p. 91-92)

No campo do novo Direito corporativo, a magistratura do trabalho constituía o pilar da nova ordem, porque aplicava no plano da dimensão coletiva dos conflitos de trabalho os tradicionais instrumentos da ordem jurídica: 0 contrato e o juízo.

0 Estado, na concepção carneluttiana, interferia diretamente no conflito social, mas garantia, por meio do Direito, a delimitação de seus próprios limites. Deste ponto de vista, a lei de 1926 renovava a ideia de um Estado que se colocava como juiz e regulador dos conflitos entre as partes, mas não de um Estado que quer subordinar a dimensão social por meio de um controle totalitário, daqui a redução do conflito coletivo em uma série de conflitos individuais. Nesta ótica, a instituição da magistratura do trabalho podia ser legitimada como um instrumento jurídico criado pelo Estado para garantir si mesmo dos novos conflitos emersos da economia industrial moderna (VIANNA, 1938, p. 83).

$\mathrm{Na}$ verdade, tanto Carnelutti no debate jurídico e politico italiano quanto Vianna naquele brasileiro estavam preocupados em dissociar o corporativismo da Lei Rocco do projeto totalitário fascista de estabelecer a extensão do poder do Estado de tal forma que ele anularia a fronteira entre público e privado. Tratou-se claramente, como vimos, de uma sofisticada defesa jurídica da acusação, no caso de Carnelutti, de ter apoiado a magistratura do trabalho, ou, no caso de Vianna, de tê-la introduzida no direito do trabalho brasileiro, dado que ambos estavam cientes de que o significado mais profundo da magistratura do trabalho reside precisamente na possibilidade do Estado totalitário de garantir seu interesse como interesse superior que transcende 0 interesse de cada categoria, até o ponto de privar - este é o pilar do projeto de Rocco - o sindicato, enquadrado no Estado, da 
prerrogativa de ser uma representação livre de interesses diversos daqueles do Estado.

\section{CONCLUSÕES}

A nossa tese é que o fascismo atualizou o autoritarismo brasileiro, em busca de um novo modelo de ordem social e de organização dos processos de modernização que estavam atravessando o Brasil entre o final dos anos 1920 e os anos 1930. Nesta perspectiva, podemos concluir dizendo que a "Era Vargas" foi essencialmente uma "modernização autoritária", disponível, porém, para receber elementos totalitários, entre os quais o modelo corporativo fascista de Alfredo Rocco foi um dos mais importantes. Foi então uma apropriação criativa dentro de um contexto histórico diferente daquele da Itália fascista da época.

Com base no modelo italiano, desde a Revolução de 1930, Vargas e os arquitetos da legislação trabalhista montaram de forma original a "via brasileira para o estado autoritário de cunho corporativo", na qual se entrelaçam várias dimensões, inspiradas pelo "corporativismo puro e integral" de M. Manoilescu: a dimensão econômica. 0 corporativismo como uma "terceira via" para responder eficazmente à crise capitalista de 1929, através da intervenção do Estado na economia, com uma perspectiva necessariamente nacionalista-desenvolvimentista e industrialista, com o objetivo de quebrar a dependência do mercado internacional. A dimensão ideológico-política. 0 corporativismo como momento de máxima expressão do Estado autoritário, surgido para nacionalizar as massas amorfas e sem educação. Para a direita nacionalista e autoritária brasileira, 0 Estado corporativo era o modelo mais "adequado" para resolver o problema da distância entre o Brasil cristalizado na Constituição de 1891 e o Brasil real, lidando com a pobreza, a ignorância, a falta de cultura política e de educação. A dimensão social. 0 Estado corporativo como resposta preventiva para o perigo de uma revolução comunista no Brasil. Nesta perspectiva, era necessário neutralizar o conflito de classes que, inevitavelmente, surgiu a partir do processo de industrialização, como aconteceu nos países mais avançados, incorporando 0 sindicato no Estado em troca de uma legislação protetora do trabalho, para dar uma nova representação social em nome da solidariedade, da reconciliação e da harmonia entre as classes.

Ao mesmo tempo foi, como vimos, uma longa e complexa incorporação da "Carta del lavoro", separada do rígido contexto do partido-estado totalitário, em uma extensa legislação social, concebida à luz da nova dimensão do coletivo e 
focada na ideologia do "trabalhismo", personificada pela figura benevolente de Getúlio Vargas como "pai dos pobres".

Por estas razões, enfim, é extremamente simplificador falar de uma "cópia" do corporativismo fascista, porque se é verdade que a estrutura básica do modelo sindical brasileiro foi o sindicalismo corporativo italiano, é também verdade que 0 estadismo dirigista de Rocco foi adaptado de forma específica para o nacional desenvolvimento industrialista de cunho autoritário no Brasil, que garantiu também alguns direitos fundamentais, ao passo que as leis anteriores em matéria de proteção do trabalho eram poucas e atrasadas.

\section{REFERÊNCIAS}

BIAVASCHI, Magda. O direito do trabalho no Brasil (1930-1942): a construção do sujeito de direitos trabalhistas. São Paulo: LTR, 2007.

CARDOSO, Fernando Henrique; FALETTO, Enzo. Dependência e desenvolvimento na América Latina. Rio de Janeiro: Civilização Brasileira, 1970.

CARNELUTTI, Francesco. Teoria del regolamento collettivo del lavoro. Padova: Cedam, 1927.

COLLOR, Lindolfo. Origens da legislação trabalhista brasileira. Porto Alegre: Fundação Paulo do Couto e Silva, 1990.

FERREIRA, Waldemar. Justiça do trabalho. Revista do Trabalbo, Rio de Janeiro, n. 5, p. 233-236, 1937.

GAGLIARDI, Alessio. Il corporativismo fascista. Roma-Bari: Laterza, 2010.

GOMES, Angela Maria Castro. A invenção do trabalbismo. Rio de Janeiro: Iuperj, 1988.

LINZ, Juan. Some notes toward a comparative study of fascism in sociological historical perspective. In: LAQUEUR, Walter (Org.). Fascism. A Reader's Guide. Berkeley-Los Angeles: University of California Press, 1976.

MANN, Michael. Fascists. Cambridge: Cambridge University Press, 2004.

MANOILESCU, Mihail. O século do corporativismo. Rio de Janeiro: José Olympio, 1938.

PAXTON, Robert 0. Il fascismo in azione. Milano: Mondadori, 2005. 
PIMENTA, Joaquim. 0 sindicato verdadeiro e o sindicato fascista. Revista do Trabalho, Rio de Janeiro, n. 7, p. 15-17, 1934.

RANELLETTI, Oreste. Istituzioni di diritto pubblico. Padova: Cedam, 1937.

ROCCO, Alfredo. Che cosa è Il nazionalismo e che cosa vogliono $i$ nazionalisti. Roma: Associazione Nacionalista, 1914.

ROCCO, Alfredo. Discorsi parlamentari. Bologna: Il Mulino, 2005.

ROMITA, Arion Sayão. O fascismo no direito do trabalbo brasileiro: influência da carta Del Lavoro sobre a legislação brasileira. São Paulo: LTR, 2001.

VARGAS, Getulio. A nova política do Brasil: da aliança liberal às realizações do primeiro ano de governo, 1930-1931. Rio de Janeiro: José Olympio, 1938. v. 1

VIANNA, Francesco José Oliveira. Problemas de política objetiva. São Paulo: Companhia Editora Nacional, 1930.

VIANNA, Francesco José Oliveira. Problemas de direito corporativo. Rio de Janeiro: José Olympio, 1938.

VIANNA, Francesco José Oliveira. As diretrizes da nova política do Brasil. Rio de Janeiro: José Olympio, 1943.

VIANNA, Francesco José Oliveira. Os sindicatos são os intermediários naturais e legais entre as classes e o poder público. Revista do Trabalbo, n. 2, p. 13, 1933.

VIANNA, Francesco José Oliveira. Problemas de direito sindical. Rio de Janeiro: Max Limonad, 1943.

VIANNA, Luis W. Liberalismo e sindicato no Brasil. Rio de Janeiro: Paz e terra, 1976. 